\title{
Helicobacter pylori and Extragastroduodenal Disorders
}

\author{
Yang-Che Kuo ${ }^{1 *}$, Lo-Yip Yu' ${ }^{1}$, Chun-Ta Huang ${ }^{1}$, Kuang-Chun $\mathrm{Hu}^{1,2,3,4}$ and Shou-Chuan Shih ${ }^{1,3,4}$ \\ ${ }^{1}$ Healthy Evaluation Center, Mackay Memorial hospital, Taiwan \\ ${ }^{2}$ Graduate Institute of Clinical Medicine, National Taiwan University College of Medicine, Taiwan \\ ${ }^{3}$ Division of Gastroenterology, Department of Internal Medicine, Mackay Memorial Hospital, Taiwan \\ ${ }^{4}$ Mackay Medicine, Nursing and Management College, Taipei, Taiwan
}

Submission: March 18, 2018; Published: March 22, 2018

"Corresponding author: Yang-Che Kuo, Division of Gastroenterology, Department of Internal Medicine, Mackay Memorial Hospital, No.92, Sec. 2, Chung-Shan North Road, Taipei, Taiwan, Tel: 886-2-25433535; Email: kuoyangche@gmail.com

Keywords: Helicobacter pylori; Metabolic syndrome; Cardiovascular disease; Colon adenoma

\section{Introduction}

Peptic ulcer disease and gastric maligancydiseases are well known related to Helicobacter pylori (H.pylori) infection, and further studies have shown the H.pylori infection possible role in several extragastric disoders. There are many reports related to metabolic syndrome, cardiovascular disease and colon adenoma, in which $H$. pylori may possibly play a potencial factor. Different mechanisms of action have been proposed, ranging from the induction of an inflammatory process to the occurrence of molecular mimicry mechanisms in the human microbiota. This review summarizes the results of the most relevant studies published on these three popular topics metabolic syndrome, cardiovascular disease and colon adenoma associated with H.pylori infection.

During the past years, several studies performed have supported the possible role for $H$. pylori infection in the pathogenesis of several extragastric diseases. As well known, Helicobacter pylori (H. pylori) infection is confirmed to correlate with chronic gastritis, peptic ulcer disease, Mucosa Associated Lymphoid Tissue (MALT)-lymphoma, precancerous changes in the stomach (atrophy, intestinal metaplasia), and gastric cancer [1]. In addition, the persistence of a pathogen in an environment long thought to be sterile also resulted in insights into the pathogenesis of chronic diseases. Many of these $\mathrm{H}$. pylori-host interactions have similarities with the interactions between the gut flora and the gastrointestinal tract and may serve as paradigms for the interactions between bacteria and their hosts [2]. This chronic infection has the local production and systemic diffusion of proinflammatory cytokines, which may influence the remote organic systems and result in extragastric manifestations [3]. H. pylori could influence the process of carcinogenesis in organs other than the stomach is gaining increasing attention.

Some epidemiologic studies report a significant link between Helicobacter pylori infection and certain cardiovascular disease risk factors, suggesting that chronic inflammation caused by H. pylori promotes atherosclerosis and cardiovascular disease [4-6]. A large Japanese population study also revealed that infection with $H$. pylori was significantly and independently associated with metabolic syndrome through alterations in several metabolic parameters, and eradication of $H$. pylori might have a role in preventing metabolic syndrome [7]. Besides, $H$. pylori infection and elevated $\mathrm{HbA} 1 \mathrm{c}$ has reported a synergistic effect on the risk for colon adenoma and carotid artery plaque formation [8]. This review article is aimed at summarizing the most relevant studies about metabolic syndrome, cardiovascular disease and colon adenoma.

\section{Helicobacter pylori and Metabolic Syndrome}

Metabolic syndrome is characterized by a cluster of metabolic abnormalities including hypertension, hyperlipidemia, and hyperglycemia, in combination with visceral obesity [9]. Additionally, the status of insulin resistance is also thought to be a potential risk factor for metabolic syndrome [10]. A possible role of $H$. pylori in diabetes mellitus (DM) has been fully investigated, and higher H. pylori re-infection rate in DM patients than in general population has been shown [11]. 
A large study from Japan(totally 5,095 cases including 3,854 men and 1,241 women) reported that the prevalence rate of $H$. pylori infection was significantly higher in cases with metabolic syndrome than the rate in those without metabolic syndrome (38.6\% vs $28.0 \%, \mathrm{P}<0.001$ ) [6]. The result also found that $H$. pylori seropositivity was significantly associated with higher systolic blood pressure, lower high-density lipoprotein (HDL)cholesterol level, and higher LDL-cholesterol level by multiple linear regression analysis. It confirmed a significant association between $H$. pylori serostatus and metabolic syndrome. Another Taiwan study reported that chronic $H$. pylori infection is significantly associated with high levels of glycated hemoglobin HbA1c and type 2 DM in patients over 65 years old ( $p=0$ .001 ) and decreased levels of insulin and insulin sensitivity in subjects under 45 years old $(p=0.05)$ [12]. Similar results were obtained in a study showing a positive correlation between $H$. pylori infection and nephropathy in DM patients [13]. In a study enrolling total of 1791 ( $49.2 \%$ males, $50.8 \%$ females) of the studied population with multiple logistic regression analysis, H. pylori infection [OR $=1.50(1.12-2.00) ; \mathrm{p}=0.007]$ showed a significant association with the metabolic syndrome in men and $[\mathrm{OR}=1.45(1.09-1.94) ; 0.01]$ in women [14]. Chronic subclinical inflammation is increasingly recognized as a part of the insulin resistance syndrome $[15,16]$. Dysregulation of the inflammatory axis predicts the development of insulin resistance and type 2 diabetes mellitus. Insulin resistance and another inflammatory state, atherosclerosis, share similar pathophysiological mechanisms, mainly due to the actions of the two major proinflammatory cytokines, TNF-alpha and IL-6 [17]. In contrast, $H$. pylori eradication has being observed significantly improved blood pressure, glucose level, and lipid profile in men, suggesting a potential role of $H$. pylori in atherosclerosis and metabolic syndrome [18]. WAN, Zhengce, et al also reported $H$. pylori infection was associated with an increased prevalence of hypertension (OR, 1.23; 95\% CI, 1.04- 1.46). In addition, compared with participants not infected with $\mathrm{H}$. pylori, those with $H$. pylori infection had an increase of $0.735 \mathrm{mmHg}(95 \%$ CI, 0.101-1.369) for diastolic blood pressure and $0.723 \mathrm{mmHg}$ (95\% CI, 0.034-1.413) for mean arterial pressure [19]. A recent large cross-sectional study in Israel were accessed for 147,936 individuals 25-95 years of age who performed the urea breath test during 2002-2012, which H. pylori infected persons had increased likelihood of metabolic syndrome: adjusted odds ratio 1.15 (95\% confidence intervals (CI) 1.10-1.19). Metabolic syndrome appeared significantly increased in relation to $H$. pylori infection and gastric and duodenal ulcers [20]. These findings suggest that $H$. pylori long-term gastric inflammation might play a role in metabolic homeostasis.

\section{Helicobacter pylori and Cardiovascular Disease}

Cardiovascular disease and all-cause mortality are increased in men with the metabolic syndrome, even in the absence of baseline CVD and diabetes [21]. Because inflammation has been shown to play a key role in the destabilization of atherosclerotic plaques. Nakagawa et al. disclosed that high serologic IL-6 levels are significantly associated with $H$. pylori infection, possibly playing a role in ischemic heart disease [22]. Sealy-Jefferson et al. demonstrated that antibody levels to $H$. pylori predicted the incidence of strokes in a Mexican-American population (OR: 1.58; 95\% CI: 1.09-2.28) [23]. Carotid artery plaque is also strongly associated with CVD, and a study showed hyperglycemia combined with $H$. pylori infection was an increased risk factor for synchronous colorectal adenoma and carotid artery plaque formation.[8] Kowalski et al. found that patients infected with CagA-positive $H$. pylori show significantly greater coronary artery lumen loss and arterial re-stenosis after PTCA with stent implantation, and H. pylori eradication significantly attenuates the reduction in lumen of the coronary artery lumen in CAD patients after PTCA. In addition, the identification of DNA in atherosclerotic plaques of patients with severe CAD supports the hypothesis that $H$. pylori infection (especially CagA positive) may influence the development of atherosclerosis [24]. Besides, a trend of decrease in coronary heart disease(CHD) occurrence after early $H$. pylori eradication in addition to the significant decrease in composite end points for CHD and death, and the significantly lower cumulative CHD rate in younger patients < 65 years old with $H$. pylori treated within one year was found in a large cohort study(total of 208196 patients with peptic ulcer diseases (PUD) from the years of 2000 to 2011) such as big data from the Taiwan National Health Insurance Research Database, suggested that there was positive association between $H$. pylori eradication and CHD [25].

Both Helicobacter pylori and Chlamydia pneumoniae infections are associated with coronary heart disease, and odds ratios for abnormal electrocardiograms were 3.82 (95\% confidence interval 1.60 to 9.10 ) and 3.06 (12.33 to 7.01) in men seropositive for H.pylori and C.pneumoniae, respectively, after adjustment for a range of socioeconomic indicators and risk factors for coronary heart disease [26]. Another recent research revealed seroprevalence of specific IgG antibodies for C. pneumoniae and H. pylori showed significant increase in C. pneumoniae IgG and $H$. pylori IgG positivity among 80 patients with previously diagnosed to have CAD compared to control (P value $<0.001$ and 0.015 , respectively) [27]. In the similar studies, the association of adult coronary heart disease with $\mathrm{H}$ pylori seropositivity suggests that the early childhood environment may be important in determining the risk of CHD in adult life.

\section{Helicobacter pylori and Colon Adenoma}

There are more articless that support the biological convicing of this association with Helicobacter pylori and colon adenoma or colorectal cancer (CRC). A 2006 meta-analysis of elevan papers that analsyed this association found that those infected with $H$. pylori have an odds ratio of 1.4 for CRC [28]. Chen et al. [29] in a meta-analysis demonstrated that $H$. pylori infection indeed increases the risk of colorectal adenoma and adenocarcinoma (OR: 1.49; 95\% CI: 1.30-1.72). Compared with normal gastric 
mucosa, H. pylori gastritis arises more frequently among patients with hyperplastic polyps, adenomatous polyps, advanced adenomas, villous adenomas or adenomas with high-grade dysplasia, and adenocarcinomas [30]. In the recent study, Kim et al who suggested Helicobacter pylori infection is an independent risk factor of colorectal neoplasm for any adenoma and advanced neoplasm, and the odds ratio (OR) (95\% confidence interval [CI]) was 1.32 (1.07-1.61) and 1.90 (1.05-3.56) in participants with $H$. pylori infection and without $H$. pylori infection, respectively [31]. Furthermore, HU, Kuang-Chun, et al reported synergistic effect of hyperglycemia and Helicobacter pylori infection status on colorectal adenoma risk, which showed the prevalence of adenoma was increased with elevated $\mathrm{HbA1c}$ levels regardless of $H$. pylori status. The odds ratio (OR) for adenoma was 1.44 (95\% confidence interval [CI], 1.20 to 1.73 ) if $H$. pylori was present or 1.68 (95\% CI, 1.05 to 2.70 ) in patients who were $\mathrm{H}$. pylori-negative but had $\mathrm{HbA1c} \geq 7.0 \%$. If both conditions were present, the OR was 4.79 ( $95 \% \mathrm{CI}, 2.92$ to 7.84 ). A $1 \%$ increase in $\mathrm{HbA1c}$ was associated with an increased prevalence of adenoma by $42.4 \%$ in $\mathrm{H}$. pylori-positive subjects [32]. A similar mechanism underlying carotid artery plaque and colon adenoma formation may be related to chronic inflammation. Chiu et al. also found that elevated C-reactive protein levels were associated with colon adenoma [33]. H. pylori-related chronic gastritis could be involved in an increased risk of colorectal neoplasm that appears to be enhanced by the progression of gastric atrophy and the presence of active inflammation [34]. In detail mechanism about the connection between $H$. pylori infection and colorectal adenoma survey, Grivennikov et al. found colorectal adenoma in both human and mouse models had increased the amounts of interleukin (IL-23 and IL-17) via some bacterial products as endotoxin [35]. Endotoxin including a complex of lipopolysaccharide is part of outer membrane of gram-negative bacterium. Although H. pylori is not alone gramnegative bacterium in gut microbiota, other organisms (e.g., Bacteroides spp.) were belong gram-negative bacterium too. As noted above, $H$. pylori might be an indicator of changes in human microbiota. This finding might support the theory that H. pylori infection may have a role in the pathogenesis of colon adenoma.

\section{Conclusion}

There are more evidences about $H$. pylori infection may not be only a local gastric disease. Due to active inflammation and changing in human microbiota, more studies showed that metabolic syndrome, cardiovascular disease and colon adenoma have already been recognized as being associated with $H$. pylori infection. Besides, the synergistic effect of $H$. pylori infection with metabolic, atherosclerosis, and carcinogenesis pathway raises the question of whether eradicating $H$. pylori infection might reduce the prevalence of the diseases. The benefit of $H$. pylori eradication was not only in decreasing gastric malignancy disease but also reducing metabolic and cardiovascular disease, colorectal adenoma probability.

\section{References}

1. Chao-Hung, Yen-Hsu Chen, Khean-Lee Goh, Lin-Li, Chang et al. (2014) Helicobacter pylori and systemic disease. Gastroenterology research and practice.

2. Kusters JG, van Vliet AH, Kuipers EJ (2006) Pathogenesis of Helicobacter pylori infection. Clinical microbiology reviews 19(3): 449-490.

3. Franceschi F, Gasbarrini A, Polyzos SA, Kountouras J (2013) Exragastric diseases and Helicobacter pylori. Helicobacter 18(Supplement 1): 4451.

4. Franceschi F, Leo D, Fini L, Santoliquido A, Flore R (2005) Helicobacter pylori infection and ischemic heart disease: An overview of the general literature. Dig Liv Dis 37: 301-308.

5. Hoffmeister A, Rothenbacher D, Bode G, Persson K, März W, et al. (2001) Current infection with Helicobacter pylori, but not seropositivity to Chlamydia pneumoniae or Cytomegalovirus, is associated with an atherogenic, modified lipid profile. Arterioscler Thromb Vasc Biol 21: 427-432.

6. Ando $T$, Minami M, Ishiguro $\mathrm{K}$ (2006) Changes in biochemical parameters related to atherosclerosis after Helicobacter pylori eradication. Aliment Pharmacol Ther 4: 58-64.

7. Gunji T, Matsuhashi N, Sato H, Fujibayashi K, Okumura M, et al. (2008) Helicobacter pylori infection is significantly associated with metabolic syndrome in the Japanese population. The American journal of gastroenterology 103(12): 3005 .

8. Hu KC, Wu MS, Chu CH, Wang HY, Lin SC, et al. (2017) Hyperglycemia combined Helicobacter pylori infection increases risk of synchronous colorectal adenoma and carotid artery plaque. Oncotarget 8(65): 108655 .

9. Eckel, RH, Grundy, SM, Zimmet, P (2015) The metabolic syndrome. Lancet 365: 1415-1428.

10. Chiu HM1, Lin JT, Shun CT, Liang JT, Lee YC, et al. (2007) Association of metabolic syndrome with proximal and synchronous colorectal neoplasm. Clin Gastroenterol Hepatol 5: 221-229.

11. Marietti M, Gasbarrini A, Saracco G, Pellicano R (2013) Helicobacter pylori infection and diabetes mellitus: the 2013 state of art. Panminerva Med 55: 277-281.

12. Hsieh MC1, Wang SS, Hsieh YT, Kuo FC, Soon MS, et al. (2013) Helicobacter pylori infection associated with high HbA1c and type 2 diabetes. European journal of clinical investigation 2013, 43(9): 949956.

13. Hsieh MC, Wang SS, Hsieh YT, Kuo FC, Soon MS, et al. (2013) Association of Helicobacter pylori infection with diabetes mellitus and diabetic nephropathy: a meta-analysis of 39 studies involving more than 20,000 participants. Scand J Infect Dis 45: 930-938.

14. Nabipour I, Vahdat K, Jafari SM, Pazoki R, Sanjdideh Z (2006) The association of metabolic syndrome and Chlamydia pneumoniae, Helicobacter pylori, cytomegalovirus, and herpes simplex virus type 1 : the Persian Gulf Healthy Heart Study. Cardiovascular diabetology 5(1): 25.

15. Russell R (1999) Atherosclerosis-an inflammatory disease. New England journal of medicine 340(2): 115-126.

16. Danesh J, Whincup P, Walker M, Lennon L, Thomson A, et al. (2000) Low grade inflammation and coronary heart disease: prospective study and updated meta-analyses. Bmj 321(7255): 199-204.

17. Fernández-Real JM, Ricart W (2003) Insulin resistance and chronic cardiovascular inflammatory syndrome. Endocrine reviews 24(3): 278-301.

18. Longo-Mbenza B, Nkondi Nsenga J, Vangu Ngoma D (2007) Prevention of the metabolic syndrome insulin resistance and the atherosclerotic 
diseases in Africans infected by Helicobacter pylori infection and treated by antibiotics. Int J Cardiol 118: 1-10.

19. Wan Z, Hu L, Hu M, Lei X, Huang Y, et al. (2018) Helicobacter pylori infection and prevalence of high blood pressure among Chinese adults. Journal of human hypertension 32(2): 158.

20. Rotem R (2018) Relationships of H. pylori infection and its related gastroduodenal morbidity with metabolic syndrome: a large crosssectional study. Scientific Reports 8(1): 4088.

21. Lakka HM, Laaksonen DE, Lakka TA, Niskanen LK, Kumpusalo E, et al. (2002) The metabolic syndrome and total and cardiovascular disease mortality in middle-aged men. Jama 288(21): 2709-2716.

22. Nakagawa H, Tamura T, Mitsuda Y, Goto Y, Kamiya Y, et al. (2013) Significant association between serum interleukin-6 and Helicobacter pylori antibody levels among $\mathrm{H}$. pylori-positive Japanese adults. Mediators Inflamm 2013: 142358.

23. Sealy-Jefferson S, Gillespie BW, Aiello AE, Haan MN, Morgenstern LB, et al. (2013) Antibody levels to persistent pathogens and incident stroke in Mexican Americans. PLoS One 8: e65959.

24. Kowalski M (2001) Helicobacter pylori (H. pylori) infection in coronary artery disease: influence of $H$. pylori eradication on coronary artery lumen after percutaneous transluminal coronary angioplasty. The detection of $H$. pylori specific DNA in human coronary atherosclerotic plaque. Journal of physiology and pharmacology: an official journal of the Polish Physiological Society 52 (Suppl 1): 3-31.

25. Wang JW, Tseng KL, Hsu CN, Liang CM, Tai WC, et al. (2018) Association between Helicobacter pylori eradication and the risk of coronary heart diseases. PloS one 13(1): e0190219.

26. Patel P, Mendall MA, Carrington D, Strachan DP, Leatham E, et al Association of Helicobacter pylori and Chlamydia pneumoniae infections with coronary heart disease and cardiovascular risk factors. Bmj 311(7007): 711-714.
27. Maysaa ES, Nashwa M, Mostafa Abd (2017) Seroprevalence of Helicobacter pylori and Chlamydia pneumoniae among Patients with Coronary Artery Diseases at Mansoura University Hospital, Egypt. Int J Curr Microbiol App Sci 6(1): 629-638.

28. Zumkeller N, Brenner H, Zwahlen M, Rothenbacher D (2006) Helicobacter pylori infection and colorectal cancer risk: a meta-analysis. Helicobacter 11: 75-80.

29. Chen YS, Xu SX, Ding YB, Huang XE, Deng B (2016) Helicobacter pylori Infection and the risk of colorectal adenoma and adenocarcinoma: an updated meta-analysis of different testing methods. Asian Pac J Cancer Prev 14: 649-658.

30. Sonnenberg A, Genta RM (2013) Helicobacter pylori is a risk factor for colonic neoplasms. The American journal of gastroenterology 108(2): 208.

31. Kim TJ, Kim ER, Chang DK, Kim YH, Baek SY, et al. (2017) Helicobacter pylori infection is an independent risk factor of early and advanced colorectal neoplasm. Helicobacter 22: e12377.

32. Hu KC, Wu MS, Chu CH, Wang HY, Lin SC, et al. Synergistic effect of hyperglycemia and Helicobacter pylori infection status on colorectal adenoma risk. The Journal of Clinical Endocrinology \& Metabolism 102(8): 2744-2750.

33. Chiu HM, Lin JT, Chen TH, Lee YC, Chiu YH, et al. (2008) Elevation of $\mathrm{C}$-reactive protein level is associated with synchronous and advanced colorectal neoplasm in men. Am J Gastroenterol 103(9): 2317-2325.

34. Inoue I, Kato J, Tamai H, Iguchi M, Maekita T, et al. (2014) Helicobacter pylori-related chronic gastritis as a risk factor for colonic neoplasms. World journal of gastroenterology WJG 20(6): 1485.

35. Grivennikov SI, Wang K, Mucida D, Stewart CA, Schnabl B, et al. (2012) Adenoma-linked barrier defects and microbial products drive IL-23/ IL-17-mediated tumour growth. Nature 491(7423): 254-258.

\section{Your next submission with JuniperPublishers will reach you the below assets}

- Quality Editorial service

- Swift Peer Review

- Reprints availability

- E-prints Service

- Manuscript Podcast for convenient understanding

- Global attainment for your research

- Manuscript accessibility in different formats

( Pdf, E-pub, Full Text, audio)

- Unceasing customer service

Track the below URL for one-step submission https://juniperpublishers.com/online-submission.php 